DOI: $10.217672573-5365.100024$

\title{
Phytochemical Screening and Ex-Vivo Cardioprotective Assay of Euphorbia hirta (L)
}

\section{Md Reyad-Ul-Ferdous 1,2,3,5*, Mehedi Rahman², Mohammad Atiqur Rahman , Al Imran Ahmed ${ }^{6}$, Md Jahed Rana ${ }^{3}$, Md Ataur Rahman ${ }^{4}$ and Hossain Reza ${ }^{2}$}

${ }^{1}$ Department of Pharmacy, Progati Medical Institute, Dhaka, Bangladesh

${ }^{2}$ Department of Pharmaceutical sciences, North South University, Dhaka, Bangladesh

${ }^{3}$ Department of Pharmacy, State University of Bangladesh, Dhaka, Bangladesh

${ }^{4}$ Department of Pharmacy, Stamford University, Dhaka, Bangladesh

${ }^{5}$ Institute for Nutritional Sciences, Shanghai Institutes for Biological Sciences, Chinese Academy of Sciences, Shanghai, China

${ }^{6}$ Department of Pharmacy, University of Asia Pacific, Dhaka, Bangladesh

*Corresponding author: Md. Reyad-Ul-Ferdous (Ph. D), Lecturer, Department of Pharmacy, Progati Medical Institute, Dhaka 1216, Bangladesh, Tel: 880-1719134213; E-mail: rockyreyad@yahoo.com

Rec date: Nov 29, 2016; Acc date: Dec 26, 2016; Pub date: Dec 29, 2016

Citation: Reyad-Ul-Ferdous Md, Rahman M, Rahman MA, et al. Phytochemical Screening and Ex-Vivo Cardioprotective Assay of Euphorbia hirta (L). Cell Mol Med 2016, 2:3.

\section{Abstract}

Investigated whole plant extracts of Euphorbia hirta L were used for it possible phytochemistry as well as thrombolysis effect by using its water, ethyl acetate and ethanolic fractioned extracts. Pharmacological history of this plant promoted us to check the possible thrombolysis activities. This article demonstrated the thrombolytic activities of various extracts of Euphorbia hirta L. Whereas ethanol, ethyl acetate and water extracts demonstrated clot lysis $25.81 \%, 14.17 \%$ and $30.48 \%$ respectively. Different conformity tests of the crude extract demonstrated that Euphorbia hirta L consists of various types of glycosides, alkaloids, tannins, flavonoids, triterpenoids etc. In-vitro Euphorbia hirta lyses blood clots. Once found Euphorbia hirta may be integrated as a thrombolytic moiety for the treatment for atherothrombotic diseases. However, the present in-vitro biological evaluation of this plant forms a primary platform for further phytochemical and pharmacological studies. These potential extracts may play vital roles for discovery new clinically effective bioactive compounds. Further investigation might be elucidating, identification of cellular and molecular mechanism of action and purification of active compounds and binding capacity of active molecules with receptors.

Keywords: Euphorbia hirta Lnn; Phytochemistry; Cardioprotective activities; Bangladesh

\section{Introduction}

An important medicinal herb (Euphorbia hirta), belongs to family Euphorbiaceae [1]. Commonly functional to cure various diseases, like as intestinal diarrhea, parasites, vomiting, heartburn, amoebic dysentery and peptic ulcers, warts, tinea, scabies, fungal afflictions, thrush, and measles, aphthae, as well as respiratory system disorders (including emphysema, asthma, bronchitis, laryngeal spasms, coughs, colds and hay fever) [2,3]. Several phytochemical studies revealed that $E$. hirta contains vital phyto-constituents like as quercitrin, rutin, myricitrin, gallic acid euphorbin- $A$, quercitin, and $\beta$-amyrin, 24methylenecycloartenol, $\beta$-sitosterol, ephorbin- $B$, euphorbin- $C$, euphorbin- $D$, heptacosane, $n$-nonacosane [4,5] tinyatoxin, shikmic acid, choline, camphol, afzelin and quercitol derivatives containing chtolphenolic acid and rhamnose [6].The polyphenolic extract of E. hirta has antiamoebic [7] and antispasmodic activity [8] Quercitrin, a flavanoid glycoside, isolated from the herb showed an antidiarrheal activity [9-11]. It is reported to have a relaxation effect on respiration [11]. The alcoholic extract of whole plant shows hypoglycemic activity in rats [6]. It has a sedative effect on the genitorurinary tract [12]. Modern studies reveal that E. hirta herb shows anti-inflammatory, antimalarial, antibacterial, antiasthmatic, antidiarrheal, galactogenic, anticancer, antifertility, antioxidant, antifungal and antiamoebic activities [13]. Further research needs to isolation purifications of lead compounds as well as mechanisms of actions of $E$. hirta.

\section{Materials and Methods}

\section{Plant material preparation}

The plant material named as E. hirta was selected based on its medicinal uses the plant's leaves were identified by the Bangladesh Forest Research Institute (BFRI), Chittagong. The plants were collected from phartoly Chittagong. It was then separated and cleaned from impurities. The collected plant was dried under shadow in room temperature and then 
macerated $\left(37^{\circ} \mathrm{C} \pm 2^{\circ} \mathrm{C}\right)$ for 3 hours at hot air oven. Almost 250 gm powders crude extracts were dissolved in $500 \mathrm{ml}$ methanol (95\%) following cold extraction for further used [14]. Afterward dissolved extract was kept couple of days under shaker for proper dissolution then solutes filtered through Buchner funnel then again dried for evaporation of methanol at water bath $\left(40^{\circ} \mathrm{C}\right)$ and extracts were preserved at $<4^{\circ} \mathrm{C}$ for further used [15].

\section{Primary phytochemical screening}

The powdered form of the plant extracts was conducted for phytochemicals test following methods described by $\mathrm{Md}$. Reyad-ul-ferdous [16-19]. The test was done to find the presence of active constituents such as flavonoid, triterpenoids, alkaloids, steroids, tannin, and glycoside by the following procedure:

Test for flavonoids: A small amount of an alcoholic extract of the plant material was treated with a few drops of concentrated hydrochloric acid. Besides concentrated hydrochloric acid, $\mathrm{Mg}$ was added in order to realize flavonoids detection. A red color was developed immediately, which show the existence of flavonoids $1 \mathrm{gm}$ extracts were dissolved in $50 \mathrm{ml}$ water for further phytochemical screening.

Test for glycosides: Little amount of an alcoholic extract was dissolved in $1 \mathrm{ml}$ of water and inserted a few drops (aqueous sodium hydroxide solution) which developed yellow color which demonstrated presence of glycosides in plant.

Test for alkaloids: Almost 0.5 gm of the extract was added in $5 \mathrm{ml}$ of $1 \%$ hydrochloric acid stirred on a steam bath and filtered; few drops of potassio-mercuric iodide solution (Mayer's reagent) were added in $1 \mathrm{ml}$ of that filtrate. A white or creamy white precipitate was formed which specify the existence of alkaloids in plant.

Test for tannins: $1 \mathrm{ml} 5 \%$ ferric chloride solutions were added in $5 \mathrm{ml}$ crude extract then orange precipitate was formed which specify the existence of tannins.

\section{Tests for carbohydrates:}

Molisch's test: Freshly prepared $10 \%$ alcoholic solution of alpha-naphtha ( 2 drops) was added in a test tube containing 2 $\mathrm{ml}$ of an aqueous extract of the plant material and mixed thoroughly. $2 \mathrm{ml}$ of concentrated Sulfuric acid was added of inclined test tube and observed a layer below the aqueous solution. If a carbohydrate is present, then a red or reddish violet ring was formed at the junction of the two layers. On standing or shaking a dark purple solution was produced then it was shaken and allowed to stand for two minutes afterward diluted with water $(5 \mathrm{ml})$. Immediate a dull violet precipitate was formed which indicates the presence of carbohydrates.

Benedict's test: In $0.5 \mathrm{ml}$ of an aqueous extract of the plant material added $5 \mathrm{ml}$ of Benedict's solution. Then it was boiled for 5 minutes and allowed to cool spontaneously. Cuprous oxide red precipitate was developed which indicates the existence of reducing sugar.
Test for resins: A few amounts of chloroform or ethanolic crude extract was dissolved in $5 \mathrm{ml}$ to $10 \mathrm{ml}$ of acetic anhydride followed by gentle heat. It was cooled and $0.05 \mathrm{ml}$ of sulfuric acid was added then no bright purplish red color was produced which indicates the absence of resins.

Test for anthraquinone glycosides: $5 \mathrm{ml}$ of chloroform shaken with $0.5 \mathrm{gm}$ of the powdered plant bark in a test tube for at least 5 minutes and filtered. An equal volume of filtrate and $10 \%$ ammonia solution was shaken. No bright pink formation, violet or red color in the aqueous (upper) layer specifies the absence of free anthraquinones.

\section{Steroids test:}

Salkowskis test: $2 \mathrm{ml}$ of crude chloroform extract carefully added in $1 \mathrm{ml}$ of concentrated sulphuric acid of the inclined test tube. A red color is formed in the chloroform layer if steroids are present.

\section{Cardioprotective Assay}

The thrombolytic properties were performed for evaluation of cardioprotective drugs moieties. All the crude extract was evaluated for thrombolytic activity by the method and modified by Md. Reyad-ul-Ferdous [15] by using standard streptokinase (SK). In brief, $100 \mathrm{mg}$ plant extracts were suspended in distilled water $(10 \mathrm{~mL})$ then kept overnight. The soluble supernatant was collected and filtered by using a 0.22 $\mu$ syringe filter for further use. $500 \mu \mathrm{L}$ venous blood drawn from human healthy volunteers and scattered in different sterile pre-weighed micro-centrifuge tube for clot lysis then incubated at $37^{\circ} \mathrm{C}$ for 45 minutes for clot formation. The serum was completely removed without disturbing the clot, after clot formation and the clot weight was determined. Each microcentrifuge tube with the pre-weighed clot was added by 100 $\mu \mathrm{L}$ aqueous solutions of different partitioned and crude extracts. Then, $100 \mathrm{mg}$ of distilled water and $100 \mu \mathrm{L}(30,000$ I.U) of commercial streptokinase (SK) were separately added to the control tube as negative and positive controls, correspondingly.

All the micro-centrifuge tubes were kept for 90 minutes at $37^{\circ} \mathrm{C}$ incubation and observed for clot lysis. The released fluid was removed after incubation and tubes were reweighed to examine the difference in weight after clot disruption.

$\%$ of clot lysis was calculated by given formula:

$\%$ of clot lysis $=$ (weight of released clot/clot weight $) \times 100$

\section{Statistical Analysis}

Herbal extracts of Euphorbia hirta clot lysis percentage was conducted by paired t-test analysis (SPSS-20). Whereas clot lysis is demonstrated as a percentage as well as $p$ value $<0.0001$ was considered as significant.

\section{Results and Discussions}

Euphorbia hirta ethanol extract of the bark were performed qualitative phytochemical tests. The Euphorbia hirta revealed 
of several chemical tests for the detection and identification of chemical moieties are mentioned in the Table 1.

The present phytochemical study indicates several potential phytochemical moieties available in the plant parts which are responsible for various pharmacological activities. These are potential phyto-constituents for vital medication against several diseases. Further investigation need to depth analysis for isolation, identification and purification of phytoconstituents and different mode of action [15-17].

Table 1 Chemical constituents identified in the bark extract.

\begin{tabular}{|l|l|}
\hline Test & Plant Parts (Bark) \\
\hline Flavonoid test & Present \\
\hline Tannin test & Present \\
\hline Glycoside test & Present \\
\hline Alkaloid test & Present \\
\hline Anthraquinone test & Absent \\
\hline Carbohydrate test & Molisch's Test-Present \\
\cline { 2 - 2 } & Benedict's Test-Present \\
\hline Resin test & Absent \\
\hline Steroid test & Present \\
\hline
\end{tabular}

In Addition, a positive control (1500000 I.U.) of $100 \mu \mathrm{l}$ of streptokinase to the clots incubation at $37^{\circ} \mathrm{C}$, along with 90 minutes which showed $69.35 \%$ clot lysis. Whereas negative control showed only negligible colt lysis (6.23\%) Clots when treated with $100 \mu \mathrm{l}$ sterile distilled water. After treatment of clot with Euphorbia hirta (E), Euphorbia hirta (EA) Euphorbia hirta (W) demonstrated $25.81 \%, 14.17 \%$ and $30.48 \%$ clot lysis respectively whereas mean percentage of clot lysis were more than water clot lysis. The thrombolytic properties are possibly due to the plant's diverse moieties like as tannins, terpenoids and flavonoids [20].

Table 2 Effect of herbal extracts on in vitro clot lysis.

\begin{tabular}{|l|l|l|}
\hline Sample & $\begin{array}{l}\text { Clotlysis } \\
\text { (mean } \pm \text { SD) }\end{array}$ & $\begin{array}{l}\text { P value with negative } \\
\text { control (water) }\end{array}$ \\
\hline $\begin{array}{l}\text { Streptokinase (used as } \\
\text { Positive control) }\end{array}$ & $69.35 \pm 1.88$ & $<0.0001$ \\
\hline Euphorbia hirta (E) & $25.81 \pm 4.22$ & $<0.0001$ \\
\hline Euphorbia hirta (EA) & $14.17 \pm 3.55$ & $<0.0002$ \\
\hline Euphorbia hirta (W) & $30.48 \pm 5.51$ & $<0.0001$ \\
\hline
\end{tabular}

Ethanol extracts $=\mathrm{E}$, Ethyl-acetate extracts $=\mathrm{EA}$, and water $=\mathrm{W}$. Herbal extracts of Euphorbia hirta was statistically demonstrated significance clot lysis percentage that was conducted by paired t-test analysis (SPSS-20) Streptokinase used as positive thrombolytic control as well as sterile distilled water used as negative control. Whereas clot lysis is demonstrated as a percentage as well as $p$ value $<0.0001$ was considered as significant

Purification of the active principles of the plant leads for the observed biological effects [21]. Euphorbia hirta herbal extracts demonstrated significance percent clot lysis with appropriate controls is shown Table 2.

\section{Conclusion}

Euphorbia hirta (Ethanol), Euphorbia hirta (Ethylacetate) and Euphorbia hirta (Water) demonstrated clot lysis 25.81\%, $14.17 \%$ and $30.48 \%$ respectively. Euphorbia hirta lyses blood clots in vitro, however, in vivo clot dissolving properties yet to be discovered. Once found Euphorbia hirta may be incorporated as a thrombolytic agent for the improvement of the patients suffering from atherothrombotic diseases.

However, the present in vitro biological evaluation of this plant forms a primary platform for further phytochemical and pharmacological studies. These promissory extracts open the possibility of finding new clinically effective bioactive compounds. Further investigation might be elucidating, identification of molecular mechanism of action and purification of active compounds and binding capacity of active molecules with receptors as well as identify specific compound for this activity among existence compounds.

\section{Ethical Consent}

Blood samples were withdrawn from those healthy persons who were volunteers themselves and, after getting clearance from our institutional ethical committee.

\section{Conflict of Interest}

All authors declare that there is no conflict of interest.

\section{Author Contributions}

All authors were equally contributed

\section{References}

1. Huang L, Chen S, Yang M (2012) Euphorbia hirta (Feiyangcao): A review on its ethnopharmacology, phytochemistry and pharmacology. J Med Plants Res 6(39): 5176-5185.

2. Anonymous (1986) Phytochemical investigation of certain medicinal plants used in Ayurveda. CCRAS, New Delhi.

3. Ben Cao ZH (1999) Shanghai Sci-tech Press 4: 788.

4. Rastogi RP, Mehrotra BN, Sinha S, Seth R; Central Drug Research Institute (India), Council of Scientific \& Industrial Research (India) (1990) Compendium of Indian medicinal plants, In: Pant P (Ed.) (3rdedn.) Volume 1. Publications \& Information Directorate.

5. Rastogi RP, Mehrotra BN (2002) 4th Lucknow, India: Central Drug Research Institute; Compendium of Indian Medicinal Plants.

6. Sood SK, Bhardwaj R, Lakhanpal TN (2005) Ethnic Indian plants in cure of diabetes. India: Scientific Publishers;

7. Tona L, Kambu K, Ngimbi N, Mesia K, Penge O, et al. (2000) Antiamoebic and spasmolytic activities of extracts from some antidiarrhoeal traditional preparations used in Kinshasa and Congo. Phytomedicine 7: 31-38. 
8. Gnecco S, Perez C, Bittner M, Silva YM (1996) Distribution pattern of $n$-alkanes in Chilean species from the Euphorbiaceae family. Bol Soc Chil Quim 41: 229-233.

9. Galvez J, Zarzuelo A, Crespo ME, Lorente MD, Ocete MA, et al. (1993) Antidiarrheal activity of Euphorbia hirta extract and isolation of an active flavanoid constituent. Planta Med 59: 333-336.

10. Galvez J, Crespo ME, Jimenez J, Suarez A, Zarzuelo A (1993) Antidiarrheic activity of quercitrin in mice and rats. J Pharm Pharmacol 45(2): 157-159.

11. Chopra RN, Chopra IC, Handa KL, Kapur LD (1994) Calcutta, India: Academic Publishers; Indigenous drugs of India.

12. Kirtikar KR, Basu BD (2003) Indian medicinal plants with illustrations. Dehradun, India: Oriental Enterprises;

13. Kumar S, Malhotra R, Kumar D (2010) Euphorbia hirta: Its chemistry, traditional and medicinal uses, and pharmacological activities. Pharmacogn Rev 4(7): 58-61.

14. Md. Reyad-Ul-Ferdous, Sayma Akhter, Md. Zahirul Islam Khan, Md. Eshak Khan, et al. (2014) Ex-vivo anti-inflammatory and antimicrobial activities of the leaves of Bauhinia acuminata. Am J Life Sci 2(5): 267-270.

15. Reyad-ul-Ferdous M, Alam TT, Islam MA, Khan MZI, Tasnim F, et al. (2014) Ex-vivo cardioprotective and cytotoxic screening of fruits of parmentiera cereifera seem. Biol Med 6: 219.
16. Reyad-ul-ferdous Md, Asif Hassan Md, Abdullah N, sarker M, Hafiz (2014) Preliminary in vitro phytochemical screenings of the barks of Parmentiera cereifera Seem. Int J Innovative Appl Res 2 (7): 57-60.

17. Ansari P, Azam S, Reyad-ul-ferdous Md, Hossain A, Tasana A (2015) Potential Investigation of Anti-Inflammatory Activity and Phytochemical Investigations of Ethanolic Extract of Glycosmis Pentaphylla Leaves. Am J Biomed Res 3(1).

18. Ghani A (2003) Medicinal plants of Bangladesh. (2ndedn). The Asiatic Society of Bangladesh 1-17.

19. Reejith PS, Praseeja RJ, Asha VV (2012) A review on the pharmacology and phytochemistry of traditional medicinal plant, Glycosmis pentaphylla (Retz.) Correa J Pharm Res 5 (5): 27-23.

20. Dwivedi S (2007) Terminalia arjuna Wight \& Arn.-A useful drug for cardiovascular disorders. J Ethnopharmacol 114: 114-129.

21. Reyad-ul-Ferdous M, Azam MG, Hossain MD (2014) Phytochemical screening, in-vitro membrane stabilizing and thrombolytic activities of Lophopetalum javanicum. Int J Pharm Sci Res 5(2): 350-353. 